electrical. The drying apparatus is divided into three groups and consists of two large hydro-extractors, a drying tumbler and a drying room. The ironing room is airy, spacious, and lighted by large windows. The electric lighting is specially designed to give perfect illumination on the work and prevent glare in the eyes of the workers. Electric hand-operated irons are installed on both sides of two long tables adequately lighted from both natural and electrical sources. There are also a collar-finishing table, two large press ironers for coats, suits, etc., and one small press ironer. A calendering machine for flat work is notable by the absence of steam. The bed of the machine is electrically heated and the roller hollow and perforated. The steam which would otherwise rise when the damp articles are heated enters the roller and is drawn off by a fan through an exhaust pipe to the outside of the building.

\section{The Dionne Quintuplets}

AN editorial in the May issue of the Statistical Bulletin written on the occasion of the sixth birthday of the Dionne quintuplets on May 28 points out that never before has a similar event been recorded, as no other quintuplets have ever survived more than a few hours after birth. The five sisters, who were premature and tiny at birth, by living to the age of six have also surpassed the record of many normal full-born infants. Although about 94 per cent of all newborn baby girls live to the age of six, the chance of any group of five baby girls surviving to that age is appreciably smaller, namely, 75 per cent. At their present age each of the Dionne children has an even chance of living sixty-three years more. The editorial also points out that the Dionne quintuplets are fortunate not only in being born at a time when the knowledge of how to control sickness and death is being constantly extended, but even more so in having been attended by Dr. Dafoe, who used all the expedients of modern medical science on their behalf. As regards the special hazards to life and health facing the Dionne children in their coming year of life, the records of the Metropolitan Life Insurance Company show that accidents at the age of six are by far the greatest danger to both boys and girls. Next, but causing considerably less than half as many deaths, come influenza and pneumonia, closely followed by appendicitis, heart disease and tuberculosis.

\section{A New Museum at Leicester}

THE opening on July 23, 1940, of the Chantry House and Newarke Houses, the former dating from 1512 and the latter a century later, as a regional museum, illustrates one successful method of preserving and using characteristic examples of local architecture (Museums Journal, 40, 173; 1940). More than a quarter of a century ago these houses were threatened with destruction with a view to the erection of factories in their place; but the intervention of a few public-spirited citizens and the interest of Leicester Corporation saved the site and buildings. The new museum, to be known as the
Leicester and County Museum, is planned, according to the trust deed, "for the purpose of telling the story of the City and County of Leicester in ages past and illustrating its condition for the time being and exhibiting suggestions for its reform and improvement and the promotion and extension of artistic culture and scientific knowledge". The War has delayed the fulfiment of these projects, but a beginning has been made, and the exhibits of civic ceremonial relics, early pieces of Corporation plate, wearing apparel of the eighteenth and nineteenth centuries, military uniforms, and agricultural and domestic implements, indicate the lines on which development will proceed. At present only the ground floor is being used, but the hope is expressed that soon other parts of the buildings will contain their own special collections.

\section{Comets}

Harvard College Observatory Card 531 announces the discovery of Comet Whipple, $1933 \mathrm{f}$, by Mr. L. E. Cunningham on September 1, at Oak Ridge. Photographs made through passing clouds with the 12-inch Metcalf refractor gave the following positions :

\begin{tabular}{|c|c|c|c|c|c|c|c|}
\hline \multirow[t]{2}{*}{1940 U.T. } & \multicolumn{3}{|c|}{ R.A. $1950 \cdot 0$} & \multirow{2}{*}{\multicolumn{2}{|c|}{ Dec. }} & \multirow{2}{*}{ Mag. } & \multirow{2}{*}{ Diam. } \\
\hline & $\mathrm{h}$ & & $\mathrm{s}$ & & & & \\
\hline Sept. 1·1486 & 22 & 34 & $08 \cdot 1$ & $-0^{\circ}$ & $15 \cdot 9^{\prime}$ & $15 \cdot 5$ & $10^{\prime \prime}$ \\
\hline 1. 1895 & 22 & 34 & $06 \cdot 5$ & $-0^{\circ}$ & $16 \cdot 2^{\prime}$ & $15 \cdot 1$ & \\
\hline
\end{tabular}

Perihelion passage would appear to be Jan. $22 \cdot 464$, 1941, which is about 0.23 day earlier than was predicted. The following ephemeris uses the corrected values of $T$, and gives small residuals for the above positions :

\begin{tabular}{|c|c|c|c|c|c|c|c|}
\hline \multirow[t]{2}{*}{1940 U.T. } & \multicolumn{3}{|c|}{ R.A. } & \multirow{2}{*}{\multicolumn{2}{|c|}{ Dec. }} & \multirow[t]{2}{*}{$r$} & \multirow[t]{2}{*}{$\Delta$} \\
\hline & $\mathrm{h}$ & $\mathrm{m}$ & s & & & & \\
\hline Nov. 3 & 22 & 24 & 30 & $6^{\circ}$ & $50 \cdot 0^{\prime}$ & $2 \cdot 538$ & $1 \cdot 955$ \\
\hline 19 & 22 & 36 & 01 & $-6^{\circ}$ & $59 \cdot 0^{\prime}$ & $2 \cdot 519$ & $2 \cdot 129$ \\
\hline Dec. 5 & 22 & 52 & 18 & $6^{\circ}$ & $26 \cdot 2^{\prime}$ & $2 \cdot 504$ & $2 \cdot 316$ \\
\hline 21 & 23 & 12 & 18 & $-5^{\circ}$ & $18 \cdot 8^{\prime}$ & $2 \cdot 494$ & $2 \cdot 505$ \\
\hline
\end{tabular}

Card 533 announces that Mr. Cunningham has found a comet on a photographic plate taken on September 5 with the 8 -inch Ross telescope at Oak Ridge. The comet appears also on eleven patrol plates taken between August 25 and September 15 at Oak Ridge or Cambridge. The estimated magnitude on August 29 was $12 \cdot 9$, but plates taken on September 9 show that the comet is slightly brighter and had a strong nucleus and a tail 2 ' long extending southward. Orbits have been computed by Cunningham and also by Maxwell and Bendler; the elements of the latter, which differ very little from those of Cunningham, are :

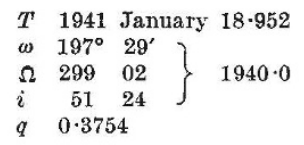

\begin{tabular}{|c|c|c|c|c|c|c|c|c|}
\hline \multicolumn{9}{|c|}{ Ephemeris $1940 \cdot 0$} \\
\hline & & & m & & & & & \\
\hline 1940 & Nov. 19 & 19 & 16 & $+35^{\circ}$ & $18^{\prime}$ & $1 \cdot 44$ & $1 \cdot 32$ & $8 \cdot 1$ \\
\hline & Dec. 21 & 19 & 18 & $20^{\circ}$ & $42^{\prime}$ & 0.76 & 0.85 & $3 \cdot 1$ \\
\hline 941 & Jan. 22 & 19 & 59 & $-29^{\circ}$ & $06^{\prime}$ & 0.38 & 0.63 & $-2 \cdot 1$ \\
\hline & Feb. 23 & 20 & 52 & $46^{\circ}$ & $30^{\prime}$ & 0.93 & $1 \cdot 40$ & $5 \cdot 4$ \\
\hline
\end{tabular}

